\title{
Influence of Platform Characteristics on Purchase Intention in Social Commerce: Mechanism of Psychological Contracts
}

\section{Shahbaz Hussain ${ }^{1}$, Ying $\mathrm{Li}^{2}$ and Wenli $\mathrm{Li}^{3}$}

\author{
${ }^{1}$ Dalian University of Technology, School of Economics and Management, Dalian, \\ China,raihussain@mail.dlut.edu.cn \\ 2 Dalian University of Technology, School of Economics and Management, Dalian, China, yingli@dlut.edu.cn \\ ${ }^{3}$ Dalian University of Technology, School of Economics and Management, Dalian, China, wlli@dlut.edu.cn
}

Received 2 August 2019; received in revised form 2 December 2019; accepted 10 December 2019

\begin{abstract}
Social commerce is an emerging platform that entails different social features to attract the attention of online consumers. Borrowing insights from the psychological contract theory, this study examines the characteristics of social commerce platforms, such as platform interactivity and rating and reviews that influence the consumers' purchase intentions. An online survey of 430 consumers was conducted on a popular social commerce site in China. Partial least squares structural equation modeling and fuzzy sets qualitative comparative analysis techniques are used to analyze this mediation model. The results reveal the positive relationships between (1) psychological contract and purchase intention; (2) platform interactivity and relational contract; and (3) rating and reviews and transactional contract. Besides, partial mediating effects of relational contract, on the relationship between platform interactivity and purchase intention, and transactional contract, on the relationship between rating and reviews and purchase intention, are also observed. Moreover, fuzzy sets qualitative comparative analysis validates the robustness of platform characteristics with psychological contracts and purchase intentions. Overall findings suggest that the platform characteristics have the potential to transform consumers' purchase intentions through psychological contracts. The study provides new insights on consumers' behavior in social commerce milieus, along with its theoretical and practical implications.
\end{abstract}

Keywords: Platform interactivity, Social commerce, Psychological contracts, Purchase intention, fsQCA 


\section{Introduction}

Social commerce is a rendezvous for people to communicate and shop using social media [25]. Social media is commonly regarded as the next great wave in technology, business, and social life [33]. In recent years, social commerce platforms are bringing more business opportunities through its rapid growth [2]. During the first quarter of 2018 , online orders through social media averaged 78.17 U.S. dollars [63]. Spending an average of more than two hours, $28 \%$ of internet users explore new products on social media and make a purchase [67]. About $30 \%$ of online consumers agree that they are likely to buy from Internet-based social networks such as Facebook, Pinterest, Instagram, Twitter or Snapchat, whereas $23 \%$ of them were influenced by social media recommendations [20]. One of the reasons to engage and purchase on these websites is that these provide various social features to meet consumers' certain expectations [56]. Nonetheless, the characteristics and psychological mechanisms of platforms that influence purchase intention remain unclear.

The spectacular rise in the number of social networking sites' users has resulted in increased accessibility for marketers and companies to extract more business opportunities. A broad range of organizations introduced social media into their marketing mix and assisted in promoting specific consumer-platform interactions [64]. Rating and reviews are also considered an integral tool in making products' characteristics clearer and helping potential consumers to make a rational decision [19]. Successful interactions between consumer and platform foster customer loyalty, readiness to try new products, trust in the platform [24], and resistance to adverse business information. Furthermore, literature also shows that one thing influencing beneficial results is the interactive nature of conversations. Content usefulness and engagement may represent distinctive features that should be effectively executed by the social commerce platform because consumers get benefits that include detailed product information, multimedia features [28], and hold the attention [38] that also inspire them to interact. For making interactivity more effective, different corporations are introducing scripted or automated bots, but these responses lose the personal touch that businesses are striving to offer to their consumers. Bot responses can be viewed as misleading or incorrect self-representations that may cause adverse attitudes and behaviors about the platform. Therefore, platforms are focusing on actual human-human interactions [29] and also real-time conversations [37], so that consumers can actively participate in interactions [38]. Social commerce sites allow people to interact with other users and also with the platform to gain information, check the ratings and reviews, and transform their impressions about that platform [22], [57]. To better understand platform interactivity effects, researchers need to examine each of these characteristics systematically as interactivity is a significant factor that will affect the purchase intention in the social commerce platform.

For the promotion of consumer-platform relationships and interactions, many organizations are applying their marketing mix through social commerce sites [64]. To build a strong bond between consumers and platform, there must be some implicit or explicit contracts, which together serve as the backbone of such bonds or exchange relationship [28], [46]. Legal contracts and psychological contracts are the two main types of exchange relationships, which have their origin in human resource management [9], [54], [56]. Earlier researchers have deeply studied the legal components of the contract [68]; however, the psychological component has been mostly overlooked. The essence of psychological contract theory has been extensively researched in e-commerce context, in which the psychological contract violation has been considered in fair detail [46]. Since, the current study revolves around the fulfillment, rather than violation, of the duties performed by the platform and, in reciprocity, by the consumers in building up and strengthening purchase intentions of the latter in social-commerce realm; therefore, psychological contract theory can be extended to social-commerce. However, in addition to the legal contract, platform characteristics help consumers to establish psychological contracts, for which consumers could have more expectations on the sellers and platforms. For example, social commerce websites usually provide tools to facilitate interactions between a buyer and a seller [2], [7]. These interactive features provided by the platform, help and assure consumers about fulfilling their expectations [37] and generate a psychological contract with the platform. In social commerce, explicit contracts are not enough to maintain consumer-platform relationships [46]; hence psychological contracts are considered to be a new and innovative idea to apply. However, extant literature has a little discussion on the meaning and types of psychological contracts in the social commerce context, which still needs further exploration.

This study seeks to address the impact of platform characteristics on purchase intention through psychological contracts. It differs from previous studies in several ways. Previous studies mainly focused on the effects of website features, quality, and security on purchase intentions in e-commerce [4], [27], [44], whereas, this study has bridged the ends by using distinctive platform characteristics on purchase intentions through psychological contracts in social commerce sites. The first main contribution of the current research is that it is based on the social exchange theory, and it lays the foundation of psychological contracts in the social commerce spectrum, by revealing its relevance and significance in social commerce. Specifically, psychological contracts are well explained in terms of consumers' response to increased social interactions and to enhance purchase intentions in social networking sites. Second, with the help of platform characteristics, it establishes the reciprocal obligations between consumers and platforms as antecedents, which are helpful in strengthening the proposed model. Third, it proposes a mediation model to investigate the influential underlying mechanisms between psychological contracts, platform characteristics, and purchase intentions. As a methodological contribution, this study utilizes recently developed fsQCA along with partial 
least squares technique to get the valid estimations of the proposed model. The findings of this study thus manage to provide some useful implications for practitioners to augment the online purchase intention in social commerce.

\section{Literature Review}

Relevant literature including purchase intentions in social commerce, platform characteristics, platform interactivity, rating and reviews, and psychological contracts are presented as follow.

\subsection{Purchase Intention in Social Commerce}

Purchase intention is portrayed as a consumer's aim to take part in web-based purchasing through social networking sites [7]. Since the objective of social commerce is to harness social networks to increase business benefits, it is significant to increase the number of transactions through users' sharing of information or recommendations [40]. Consumers' purchase intention is a valid proxy for purchase behavior, and many researchers have examined the factors that influence consumer's purchase intention. Prior studies have investigated social commerce constructs, attitudes towards information quality, and collective capabilities in surging online purchase intentions [13], [19], [24].

Moreover, some studies have also considered the consumer-platform relationship as an integral part of increasing purchase intentions [46], [58]. For a successful relationship in social commerce sites, the platform should provide some significant features like social interactions, provide useful content, and facilitate real-time communications that will be helpful in the decision-making process [2]. Given all the studies conducted so far, there are still limitations encountered by the consumers when it comes to platform interactivity in social commerce because it is not fully conceptualized to its full extent while discussing purchase intentions. Furthermore, psychological contracts are also considered essential in exchange relationships, and their impacts on purchase intentions are not fully utilized in social commerce, providing a research gap to plugin with the current study.

\subsection{Platform Characteristics}

Prior research on platform success has mainly focused on platform characteristics such as rating and reviews, forum and communities, recommendation and referrals, and interactivity features [27], [38] in an e-commerce context. Since platform characteristics have a significant role in enhancing purchase intentions, so the primary purpose of this study is to investigate these characteristics and their role in social commerce. Hence, to achieve the consumer's intentions, it is essential to ensure the main characteristics of the social commerce platform [2], [7]. This study fills the gap of platform characteristics' influence on purchase intention in social commerce through platform interactivity, i.e., content usefulness, engaging, human-human interactions, and real-time communications. Furthermore, the platform is considered to be successful if it provides ratings and reviews of previous consumers because it gives a sense of trust and satisfaction to the potential consumers [61]. Moreover, they also feel that rating and reviews are the roadmap to enhance their purchase intention [19]. This study also attempts to fill this gap in social commerce platforms.

\subsubsection{Platform Interactivity}

Platform interactivity is defined as the extent to which consumers on the platform can communicate, search useful information, and conduct significant transactions through the platform [45]. In principle, it connects online sellers with buyers, by permitting the latter to look for and search product features [72], which, in turn, leads to the consumers' buying behavior and, not to mention, strengthens their purchase intentions. Not only that, but it also constitutes the social interactions of consumers on the platforms, comprising discussions and feedbacks about the product [7]. Such discussion and feedback are valuable sources for the improvement and development of new features and services provided by the platform. Previously, the researchers have developed several models based on website interactivity in the e-commerce domain, which are also parochial [4], [27], [44]. One such model has been built to test the website interactivity as an online branding tool and to explore the relationship among the features of website interactivity, brand knowledge, and brand value [4]. Prior research is also conducted to investigate the website quality, its function, and its impact on purchase intentions [64]. The platform interactivity embodies several features like user control, responsiveness, connectedness, and playfulness [74].

Based on website interactivity theory [43], [44], [59], platform interactivity is considered as a first-order formative construct and explained on the upcoming variables that include content usefulness, engaging, human-human, and real-time communication. Content usefulness, referring to the user's motivation to interact with the platform in the future because of its useful content, including a furnished search function, detailed product information, and multimedia features [28]. Engaging, operationalized as an attempt to evaluate the perceived platform interactivity by maintaining the platform's content to keep hold of the users' attention [38] and increasing the consumers' engagement into the platform [8]. Thus, encourage them to trigger good feelings regarding the platform's worth to make further purchases. 
Human-human is related to its enabling features for communication with its other users [29]. Earlier research studies have found that consumers feel more secured and intend to buy more by providing the social presence of ecommerce platforms and their social applications [69]. Another similar study has demonstrated that potential consumers are more inclined towards the contents generated by their fellow consumers as opposed to just vendors' generated product information [50]. Real-time communication refers to the platform's ability to provide an asynchronous two-way flow of information. Social commerce sites having web 2.0 technologies are the best sources of these interactions, providing concurrent and real-time conversations between consumers and platforms [37]. However, the conceptual grounds of these constructs are well defined in e-commerce, but they are yet to evolve in social commerce. This study thus explains these significant characteristics of the platform, notably content usefulness, engaging, human-human, and real-time communication.

\subsubsection{Rating and Reviews}

Rating and reviews are conceptualized as the scores and reviews provided by actual consumers to specific products or services after using that product [19]. Ratings and reviews are authentic and reliable sources for potential consumers that are provided by actual users and are considered as the characteristics of social commerce sites [18]. Social media is an online platform that allows consumers to express their good or bad experiences and rate that specific product. These reviews persuade potential buyers about that product and help them in decision making [19]. Based on the social adoption process [2], [7], rating and reviews are essential in shaping consumers' behavioral intentions. Authentic reviews and recommendations from consumers help in building trust, which leads to the more vibrant and relevant shopping experience on social commerce platforms, thus inspiring further purchases [18], [19]. Rating and reviews are not yet studied with the psychological contracts, so this study investigates the role of rating and reviews with purchase intensions through psychological contracts in social commerce sites.

\subsection{Psychological Contracts}

Generally, psychological contract is an assumed set of reciprocal obligations among parties in action [52], [56]. In social commerce, psychological contracts are a set of reciprocal duties supposedly performed by consumers in return to a satisfying platform's experience. Much research has been conducted on psychological contracts pertain to intra-organizational relationships between an employer and employee in social commerce [54]. This intraorganization concept of psychological contracts can be well extended in appropriate manner and to considerable extent in social commerce [28], [30]. This is because, even though, the social commerce focuses more on the fulfillment of the obligations performed by the platform and, in return, by the consumers towards building strong consumer-platform relationship, yet the principle of psychological contract theory applies similarly in the social commerce as well. Therefore, psychological contracts can be rationally explained in social commerce milieus as well (social commerce and e-commerce). Based on extensive typology, psychological contracts can be categorized into either relational or transactional [46].

\subsubsection{Transactional Contracts}

Transaction contracts are defined as one party's beliefs about the other party's contractual obligations and vice versa [56]. Transactional contracts are based on short-term exchange relationship and are economical in nature; besides, such contracts are narrow in scope and definition [46]. In these contracts, the performance requirements or mutual benefits are explicitly specified [26]. In social commerce, the transactional contract is strictly pivoted to the exchange of goods and services between the buyer and the platform. Since such contracts are more about the exchange and less about building and retaining the relationship, therefore, no or little future cooperation is expected in the transactional contract [56]. From a consumer standpoint, transactional contracts consist of the buyer's perceptual beliefs about the seller's contractual obligations [46]. So, the transactional contract has bright prospects in social commerce as it has a strong influence on mutual obligations. Therefore, the significance of the transactional contract is considered more imperative from the buyers' perspective. Even though the transactional contract is a short time, but the economic exchange in such contracts is well-considered, acknowledged, and directly related to the psychology of the consumers [23]. Based on its eternal nature, in this study, the transactional contract is integrated with the platforms to have better control over social commerce dynamics by influencing consumers' purchase intentions.

\subsubsection{Relational Contracts}

Relational contracts are implicit and behavioral in their nature and the fulfillment of such contracts arise from a trustworthy relationship between the parties involved [54], [55]. A relational contract is based on non-economic/socioemotional exchanges and is open-ended, which means they do not cover any definite period [56]. However, such contracts are prone to variations over time with their broad scope and definition [52]. It is a norm for a business organization to enhance an employee's promised duties over time through raises and lateral designation changes [5] Similarly, in social commerce, the relational contract is characterized as a set of unwritten expectations between the platform and its consumers, who agree to develop a continuous consumer-platform relationship [55]. Platform and consumers have to cooperate and enrich contractual duties over time. When a platform is successful in fulfilling longterm relational obligations towards its users, then the latter also perceive they have long-term, relational obligations towards the former. The significant relational obligations of the platforms may, but not limited to, include providing a real website with no disruptions, original products, and their detailed information, a variety of products in terms of 
quality and cost, and customer value. Similarly, long-term relational obligations of the consumers also include the purchase and repurchase intentions. Based on its implied nature, a relational contract's influence can be investigated on purchase intentions in social commerce platforms in this study.

\section{Conceptual Framework and Hypotheses}

The resultant model, shown in Figure. 1, projects rating and reviews and platform interactivity constructs as independent variables, not to mention that the psychological contracts mediate the process. Furthermore, this study assumes that the platform interactivity plays a fundamental role and, thus, qualifies as a powerful construct. It helps in apprehending that whether the social commerce website is active, in terms of developing frequent seller-buyer interactions. The proposed model treats platform interactivity to be a more explicit, broader, and more abstract higher-order latent variable, which is comprised of four distinct dimensions. Moreover, purchase intention is the dependent variable, and psychological contract (both relational and transactional contracts) works as a mediator in the present research.

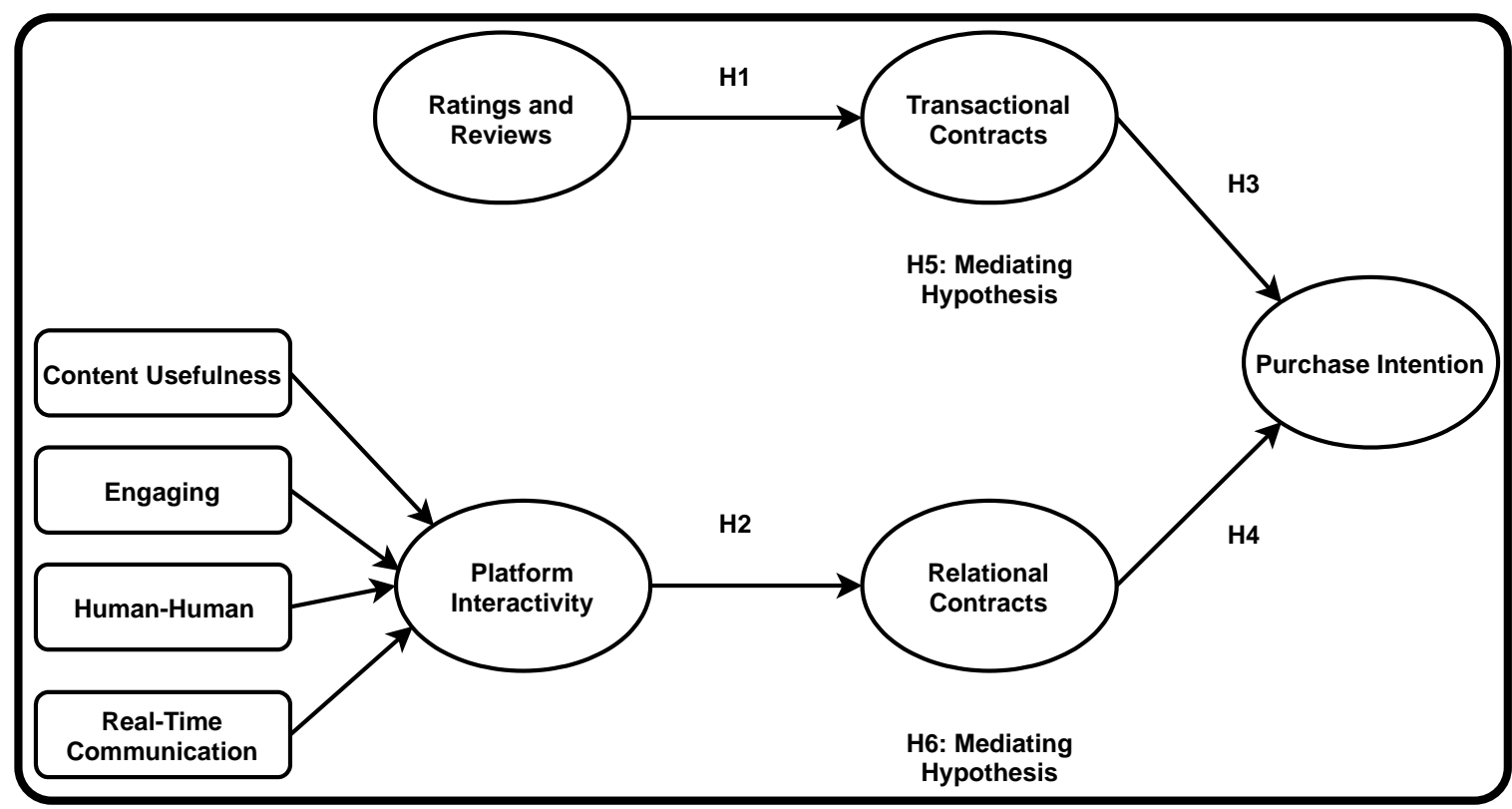

Figure 1: Conceptual framework

\subsection{Rating and Reviews}

Rating and reviews are the most powerful tool in social commerce. Online reviews can be posted on the company's websites, particular rating products, or on websites that rate products or companies and are not owned or controlled by the company that is being rated [13]. Additionally, individuals can obtain social identification and approval from the community through ratings and recommendations given by peers. Authentic reviews and recommendations from consumers develop a more vibrant and relevant shopping experience on social commerce platform that inspires more people to transact. Rating and reviews serve as 'ears and eyes' for consumers new to the platform. Positive ratings and reviews assist consumers in transacting with the platform, whereas negative force them to quit from these contractual obligations. These reviews reflect the overall perception that the platform has generally fulfilled all of its contractual obligations. Furthermore, ratings and reviews develop financial and short-term relationships with the platform that are also the characteristics of transactional contracts [56]. Whereas relational contracts represent longterm consumer-platform relationships which are not possible with rating and reviews. So, positive ratings and reviews depict that consumers are satisfied with the transactions conducted on this platform. Therefore, it is fair to conclude that rating and reviews reveal the fact that the platform fulfills all the contractual obligations. Accordingly, we can hypothesize that;

\section{H1: Rating and reviews are positively associated with transactional contract.}

\subsection{Platform Interactivity}

To build a strong consumer-platform relationship, social commerce websites support different types of socializing activities. Therefore, Platform interactivity works as stimuli and plays a crucial role in influencing the perception of consumers [44]. The fast development of e-commerce and the uniqueness of this innovative exchange station emphasize the significance of comprehending the potential power of platform interactivity as a tool to form 
relationships between platforms and consumers [44]. In this sense, platform interactivity is viewed as an essential high-tech capability for a business attempting to establish long-term relationships with its consumers [43], as it allows a reciprocal communication with the system and other users.

Moreover, Platform interactivity does not make a clear ground for developing a relationship with a transactional contract because it helps to develop a long-term relationship as explained above and do not involve monetary terms. Similarly, relational contract theory explains that parties (consumers and platform) to contract, build a relationship that integrates planning, trust, and solidarity that far exceed the terms of the original document through platform interactivity [35]. The interaction between suppliers and buyers that encapsulates the nurturing of social exchange variables implies that current and future expectations and reciprocal obligations between them are critical relational building elements [27]. Thus, we hypothesize that,

\section{H2: Platform interactivity is positively associated with relational contracts.}

\subsection{Psychological Contracts}

The role of psychological contract can be traced back to organizational behavior literature [55], [56] in which individuals who experience psychological contract violations are less likely to involve in desirable organizational behaviors [51] and are more disposed to leave the organization [53]. This indicates that individuals act favorably with the organization when they feel that the organization is going to fulfill all of its obligations [46]. Along the same lines, when we can also extend these findings to online marketplaces, where consumers with fulfilled psychological contracts are more likely to transact with the platform. Consumers generally have more faith, and favorable intention after the psychological contract has fulfilled; such consumers have more intentions to transact with the platform in online marketplaces [13]. The perception of consumers that they will get the same products and services as described by the platform gives rise to the transactional contract. Transactional contract works as a binding force in a consumer-platform relationship and, therefore, affects the attitude and behavior of consumers. We also gauge the extent to which the consumer experiences continuous support from the platform in terms of ratings and reviews by peers. Positive ratings show that the platform is fulfilling its transactional obligations. These arguments provide a solid foundation that transactional contracts and consumers' intentions are highly correlated with each other. Accordingly,

\section{H3: Transactional contract is positively associated with purchase intention.}

Previous studies have focused on the effects of interactivity issues on the relational aspects that influence consumer behavior [1]. This research study evaluates the consumer perceptions about the platform in providing its interactivity features and its promissory obligations that are implicit. Specifically, relational contract, which facilitates perceived promises, recognition, and dependence [56], helps in building a consumer-platform relationship. It also includes longterm and extensive obligations, based on the exchange of socio-emotional components such as commitment and satisfaction. It also explains the liable behavior of both parties towards each other's intentions [52]. Higher the perception of relational obligations accomplishment, the higher will be the intentions to buy. So, we can hypothesize that

\section{H4: Relational contract is positively associated with purchase intention.}

\subsection{Mediation Effects}

In the realm of social commerce, the consumers are more concerned with the components of the transactional contract, such as on-time delivery, payment methods, the refund policy, and so on, which constitute most of the consumers' expectations and interests into the platform [46]. Such transactional expectations and obligations, therefore, are the critical determinants of the consumers' attitudes and behaviors when it comes to shaping up their purchase intentions [16], [19]. In this regard, ratings and reviews are likely to be the strong testaments to making consumers believe in the transactional contract offered by the platform [18]. Consumers can access others' reviews that add an assistive touch to the online decision-making process [18]. Positive ratings and reviews explain the perception that the platform is good enough to undertake its promises and performs its contractual obligations. These transactional obligations accomplished by platform, encourage the consumer to buy from this platform. Therefore, it can be proposed that the components of transactional contract offered by the platform holds precedence [46] and plays a remarkably active mediating role in prompting the consumers to reciprocate by leaving their sincere ratings and reviews in favor or against the platform and, thus, help in formulating the purchase intentions of the potential consumers. Hence, we can hypothesize that:

\section{H5: Transactional contract mediates the relationship between rating and reviews and purchase intention.}

The significance of platform interactivity in e-commerce arises principally from its capacity to have positive long-term influences on customer perceptions and, thus, influential in [59]. Platform interactivity is characterized by its features such as content usefulness, engagement, human-human interaction, etc., which is also found to affect the intentions of the consumers towards a purchase. Consumers who experience social presence through interactions with other 
consumers may feel more comfortable, more emotionally fulfilled, and more engaged in the activity [40]. Consumers and platforms both have the "intention to accept vulnerability based upon expectations of positive intention or behavior of another" [56]. Several studies have also shown that the presence of interactive features contributes to increased feelings of telepresence on commercial websites [11] and having a more inspirational state of mind toward the platform [14]. These interactive features generate long term substantial effects on a consumer-platform relationship [43]. These bonds aid in fulfilling the reciprocal obligations between parties and enhance the intention to buy from this platform. More thoughts a consumer has about interaction feature feels more bounded with the platform in terms of relation. Moreover, more attachment with the platform increases the purchase intention of consumers. Similarly, the human-human interactions between the potential customers and platforms should be instant with least or no delays so that the consumers may feel their queries and concerns answered by the platform team and, thus, decide whether or not buy the product from the platform [29]. Having said so, it can be proposed that the relational contract act as a mediator between the platform interactivity and purchase intentions of the consumers, for such contracts fulfill the spirit of the former. Hence, it can be hypothesized that:

\section{H6: Relational contract mediates the relationship of platform interactivity and purchase intention.}

\section{Methodology}

Methodology section including measurement of constructs, pilot study, samples, and procedures are presented as follow.

\subsection{Measurement of Constructs and Pilot Study}

Platform interactivity, the independent variable, this study conceptualizes it as a higher-order formative construct and measures it through four components, i.e., content usefulness, engaging, human-human interaction, and real-time communication. Content usefulness is developed with four items and adapted from the study of Ko et al. [29]. Engaging is derived from McMillan and Hwang [38] (e.g., the platform keeps my attention) and is measured with four items. Human-Human construct is measured with four items and is taken from the study of Ko et al. [29]. Real-time communication is measured with five items adapted from McMillan and Hwang [38]. Rating and reviews, another independent variable, are conceptualized on three items that are based on the study of Hajli [19]. Transactional contract, the mediating variable, is operationalized as a buyer's perceptual beliefs about the platform's contractual obligations and is derived from the study of Pavlou and Gefen [46]. Relational contract, the other mediating variable is based on related studies [39], [41], with modifications to the wording as appropriate for our research. Purchase intentions, the dependent variable, is adapted from the study of Hajli and is measured on four items [19]. Based on the literature, a multi-item scale has been developed. Platform interactivity $(\mathrm{PI})$ and psychological contract (PC) have been established, especially for current research. All the constructs are well defined and explained in the appendix $A$ All items were measured on a 7-point Likert scale ranging from 1 (strongly disagree) to 7 (strongly agree).

An initial literature review was useful in developing an in-depth understanding of screening the primal variables discussed in this study. These variables helped define the primary constructs (platform interactivity, relational, and transactional contracts) that are studied in this research. Other variables explained in this study were well-defined in literature. Furthermore, semi-structured interviews were conducted from experts, having different backgrounds in this field of study. Literature and interviews helped us to define the primary constructs (platform interactivity, relational, and transactional contracts and were the primary source to authenticate the content validity of the questionnaire. This questionnaire was specially designed for buyers having online experience in China. Having support from literature, The English version of the questionnaire was first developed and then translated into Chinese. To ensure the accuracy of the translation, the forward and backward translation method was applied for all constructs [62]. For the ultimate validation of the questionnaire, a pilot study was additionally conducted with the help of 25 respondents having immense experiences in online shopping. After successful pilot testing, some minor changes in structure and questions were made to reduce the cultural and language differences and to improve the reliability and validity of the questionnaire.

\subsection{Sample and Procedures}

The study gathered data by providing an online survey link to 430 intensive consumers of social commerce sites. The sample population was comprised of students and instructors having the online experience, aged 18 and above, from different colleges and universities in China. This convenient sample approach within the context of online shopping was in accordance with prior researches in information systems [31]. Since the data was collected by providing an online link to the sample, so this study also checked the nonresponse biases. Nonresponse bias arises when there is a substantial difference in opinions between the actual and potential respondents [3]. Nonresponse bias refutes the outcomes of research because the survey sample cannot accurately represent the population. Fortysix earliest and 46 last responses were compared using Chi-square tests and T-test on context variables to identify the nonresponse bias. The results showed no significant differences between the two groups $(p>0.05)$, concluding that this study did not suffer from the nonresponse bias. Weitao (an extension of TaoBao) having both social and ecommerce features were used for this study. 
A total of 430 respondents were surveyed online, 237 were male $(55.1 \%)$, and 193 were female $(44.9 \%) .73 .9 \%$ of the respondents were single, and $26.1 \%$ were married. Most of the respondents were aged between 18 and 30 (79.6\%), had graduate and postgraduate education (bachelor \& master) (73.5 percent), and frequency of using social commerce sites (once a day to once a week) was $77.9 \%$. The majority of the respondents had disposable income of about 3,000 Ren Min Bi (RMB) or below (55.1 percent). Detailed demographics of the respondents are described in Table 1.

Table 1: Demographics of respondents

\begin{tabular}{|c|c|c|c|}
\hline Variables & Categories & Frequency & Percentage \\
\hline \multirow[t]{2}{*}{ Gender } & Male & 237 & 55.1 \\
\hline & Female & 193 & 44.9 \\
\hline Marital status & $\begin{array}{l}\text { Single } \\
\text { Married }\end{array}$ & $\begin{array}{l}318 \\
112\end{array}$ & $\begin{array}{l}73.9 \\
26.1\end{array}$ \\
\hline \multirow[t]{6}{*}{ Age } & $\leq 18$ & 33 & 7.7 \\
\hline & $19-24$ & 132 & 30.7 \\
\hline & $25-30$ & 177 & 41.2 \\
\hline & $31-36$ & 47 & 10.9 \\
\hline & $37-42$ & 22 & 5.1 \\
\hline & $\geq 42$ & 19 & 4.4 \\
\hline \multirow[t]{4}{*}{ Frequency of Use } & Once a Day & 126 & 29.3 \\
\hline & Once a week & 209 & 48.6 \\
\hline & Once a month & 84 & 19.5 \\
\hline & Bi-annually & 11 & 2.6 \\
\hline \multirow[t]{4}{*}{ Education } & Below and high school & 36 & 8.4 \\
\hline & Bachelor & 144 & 33.5 \\
\hline & Master & 172 & 40.0 \\
\hline & Ph.D. and above & 78 & 18.1 \\
\hline \multirow{5}{*}{$\begin{array}{l}\text { Disposable income } \\
\text { (RMB) }\end{array}$} & $\leq 3000$ & 237 & 55.1 \\
\hline & $3000-3999$ & 120 & 27.9 \\
\hline & $4000-4999$ & 43 & 10.0 \\
\hline & $5000-5999$ & 21 & 4.9 \\
\hline & $\geq 6000$ & 9 & 2.1 \\
\hline
\end{tabular}

\section{Data Analysis and Results}

In this research, data were analyzed by using SmartPLS version 3.2.7 and fuzzy sets qualitative comparative analysis (fsQCA) version 3.0. This study used the partial least square-structural equational modeling (PLS-SEM) method, a popular tool to examine the new research trends to build a model rather than confirmation [66]. This method helps address the foregoing limitations within the constructs, by measuring both reflective and formative constructs at the same time; therefore, PLS-SEM is the best fit over covariance based-structural equational modeling (CB-SEM) [15]. However, CB-SEM can usually handle only reflective models. Furthermore, the choice of PLS-SEM was made on the base of its ability to estimate causal relationships among all latent constructs simultaneously while dealing with measurement errors in the structural model [17]. Keeping in view some limitations of PLS-SEM, like causal symmetric relationships and net effects, this study also tried to overcome these limitations by employing a new technique fsQCA, which is considered a valued algorithm for solving uncertainty issues [48].

\subsection{Measurement Model Analysis}

This study evaluated the measurement model through reliability, average variance extracted (AVE), discriminant, and convergent validity using commonly accepted guidelines. Reliability was assessed first, and the recommended threshold of 0.70 was met in all constructs. These results of reliability and AVE are shown in Table 2.

Data was gathered through a single source, and it was cross-sectional, so Harman's single-factor test was used to check the common method variance (CMV) estimations [47]. Spurious covariance shared among variables has been tested since a common method is used in data collection. An exploratory factor analysis of all items of the construct's items revealed that the first two factors cumulatively account for $40.988 \%$ of the variance, with the first factor accounting for $34.613 \%$ and the second factor explaining $6.375 \%$ of the total variance. The single factor did not account for the majority of the variance, which indicates that the common method bias did not affect the data. This study also employed the approach by Liang [32] to examine common method bias (CMB). "If the method factor loadings are insignificant and the indicators substantive variances are substantially greater than their method variance" [32], suggesting that common method bias was not an issue. The average of $\left(\mathrm{Ra}^{2}\right)$ was considerably higher than their method variances $\left(\mathrm{Rb}^{2}\right)$ with a ratio of 803.4: 1 [32]. Hence, CMB remained not an issue. 
Table 2: Reliability, AVE, and correlations

\begin{tabular}{|l|l|l|l|l|l|l|l|l|l|l|l|}
\hline Constructs & CU & EN & HH & IN & RC & RR & RTC & TC & AVE & CR & $\alpha$ \\
\hline CU & $\mathbf{0 . 8 4 3}$ & & & & & & & & 0.71 & 0.907 & 0.863 \\
\hline EN & 0.178 & $\mathbf{0 . 8 5 3}$ & & & & & & & 0.727 & 0.914 & 0.875 \\
\hline HH & 0.166 & 0.184 & $\mathbf{0 . 8 5 1}$ & & & & & & 0.725 & 0.913 & 0.873 \\
\hline IN & 0.502 & 0.455 & 0.498 & $\mathbf{0 . 8 5 2}$ & & & & & 0.727 & 0.914 & 0.874 \\
\hline RC & 0.498 & 0.498 & 0.513 & 0.718 & $\mathbf{0 . 7 8 2}$ & & & & 0.612 & 0.882 & 0.814 \\
\hline RR & 0.377 & 0.368 & 0.371 & 0.526 & 0.552 & $\mathbf{0 . 8 7 0}$ & & & 0.756 & 0.925 & 0.892 \\
\hline RTC & 0.137 & 0.22 & 0.223 & 0.515 & 0.528 & 0.434 & $\mathbf{0 . 8 3 9}$ & & 0.705 & 0.923 & 0.895 \\
\hline TC & 0.335 & 0.395 & 0.387 & 0.55 & 0.523 & 0.356 & 0.382 & $\mathbf{0 . 8 1 3}$ & 0.661 & 0.907 & 0.872 \\
\hline
\end{tabular}

Note: $\mathrm{CU}=$ content usefulness, $\mathrm{EN}=$ engaging, $\mathrm{HH}=$ human-human, IN=purchase intention, $\mathrm{RC}=$ relational contract, $\mathrm{RTC}=$ real-time communication, RR=rating and reviews, TC=transactional contract, $\alpha=$ Cronbach's alpha. Bold items are the square root of the AVEs.

Validating higher-order formative factors requires a bit more finesse. Following Marakas et al., this research was intended to confirm the existence and validation of the four dimensions of platform interactivity (PI) [36]. First, this study assessed the significance of the indicators. In the case of these constructs, we included the effects from first to second-order factors. The calculated results provided reliable provision to us for the four dimensions as traits of $\mathrm{PI}$ as a second-order construct in Table 3.

Table 3: Upward dimension effects for platform interactivity

\begin{tabular}{|l|l|l|l|l|l|}
\hline Relationship & Type & Original mean & Standard deviation & T Statistic & P-value \\
\hline $\mathrm{CU} \rightarrow \mathrm{PI}$ & 1st $\rightarrow$ 2nd & 0.334 & 0.031 & 10.696 & 0.000 \\
\hline $\mathrm{EN} \rightarrow \mathrm{PI}$ & 1st $\rightarrow$ 2nd & 0.372 & 0.027 & 13.867 & 0.000 \\
\hline $\mathrm{HH} \rightarrow \mathrm{PI}$ & 1st $\rightarrow$ 2nd & 0.374 & 0.029 & 13.071 & 0.000 \\
\hline $\mathrm{RTC} \rightarrow \mathrm{PI}$ & 1st $\rightarrow$ 2nd & 0.508 & 0.031 & 16.156 & 0.000 \\
\hline
\end{tabular}

Second, we also have executed further tests to check the severity of multicollinearity. All constructs have variance inflation factors values less than 3, which are within the threshold of 3.3 [16].

\subsection{Structural Model Assessment}

The model describes that the adjusted $R^{2}$ is sufficient: $R^{2}=55.8 \%$ for Purchase Intention, $R^{2}=66.7 \%$ for $R C$ and $R^{2}=12.7 \%$ for TC. The major paths from characteristics to behaviors to outcomes are all significant at the $99.9 \%$ confidence level. The model explains that PCs, antecedents, and consequences impact $55.8 \%$ on the social commerce site's purchase intention.

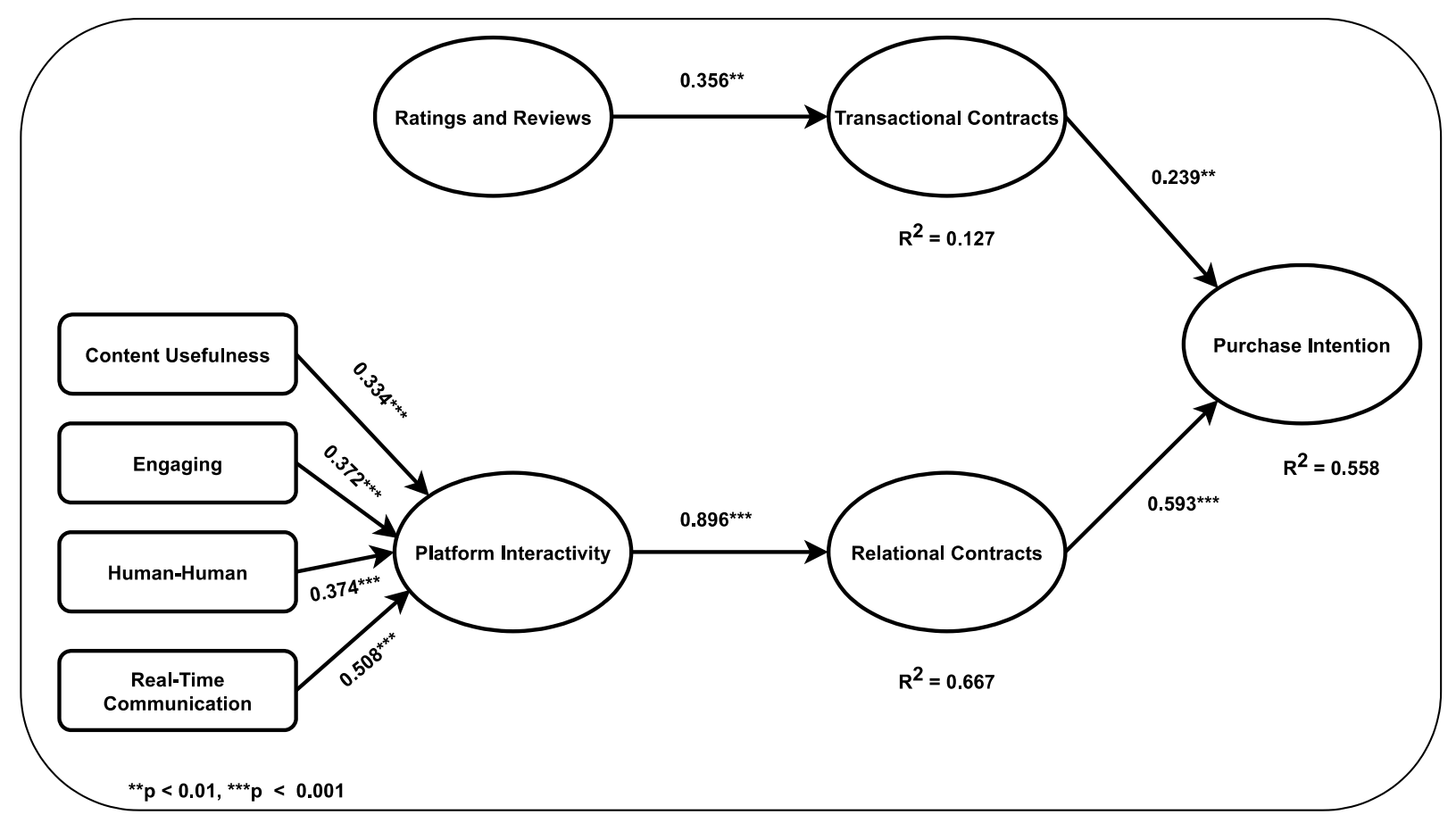

Figure 2: PLS results of research model 
In relation to $\mathrm{H} 1$, results showed that rating and reviews were significantly related to transactional contracts (TC) $(\beta=$ $0.356, t=8.463, p<.01)$. H2 examined the effects of platform interactivity on relational contracts $(R C)$. Interactivity was influencing significantly to $\mathrm{RC}(\beta=0.896, t=30.415, p<.01)$. H3 examined the outcomes of TCs on purchase intention. TC was significantly related to purchase intention $(\beta=0.239, t=6.331, p<.01)$. H4 examined the effects of $R C$ on purchase intention. RC were significantly related to purchase intention $(\beta=0.593, t=17.885, p<.01)$. Table 4 and Figure 2 show all the hypothesis results.

Table 4: Hypothesis results

\begin{tabular}{|l|l|l|l|l|l|l|}
\hline Relationship & Original mean & Standard deviation & T Statistic & P-value & $\mathrm{f}^{2}$ & Hypothesis supported? \\
\hline $\mathrm{RR} \rightarrow \mathrm{TC}$ & 0.356 & 0.042 & 8.463 & 0.002 & 0.026 & Yes \\
\hline $\mathrm{PI} \rightarrow \mathrm{RC}$ & 0.896 & 0.029 & 30.415 & 0.000 & 0.343 & Yes \\
\hline $\mathrm{RC} \rightarrow \mathrm{IN}$ & 0.593 & 0.033 & 17.885 & 0.000 & 0.72 & Yes \\
\hline $\mathrm{TC} \rightarrow \mathrm{IN}$ & 0.239 & 0.038 & 6.331 & 0.004 & 0.679 & Yes \\
\hline
\end{tabular}

Furthermore, effect size $\mathrm{f}^{2}$ was examined to inspect the nominal effect of the model [10]. The model anticipated that RR on TC $\left(f^{2}=0.026\right)$ has a small effect size, whereas PI on $R C\left(f^{2}=0.343\right), R C$ on purchase intention $\left(f^{2}=0.72\right)$, and TC on purchase intention $\left(f^{2}=0.679\right)$ have a significant effect size.

\subsection{Mediation Analysis}

To test for the mediating role through $\mathrm{H} 6$ and $\mathrm{H} 7$, we employed the latest conventions [21], [34], [75], focused on bootstrapping. For mediating effect, the indirect effect must also be significant [15]. After analyzing the model, we found that PI (significantly positive) had a high and significant effect on RC, which in line has a robust relationship with purchase intentions. The indirect effects of PI through the mediator RC were both significant. The same was the case recorded with ratings and reviews. The indirect effect of rating and review through the mediator TC was significant and positive. The indirect effect is computed by multiplying the direct and indirect effect to evaluate the magnitude of the indirect effect, and we have calculated the variance accounted for (VAF), which ascertains the size of the indirect effect in relation to the total effect (VAF=indirect effect/total effect), getting a value of $34.56 \%$ for platform interactivity and $33.93 \%$ for rating and reviews. It concludes that partial mediation exists (see Table 5).

Based on a thorough examination, it is inferred that both models (i.e., measurement model and structural model) are validated. Also, the outcomes show that the proposed model of this study has noteworthy predictive relevance and explanatory power.

Table 5: Mediation effect of the model

\begin{tabular}{|l|l|l|l|l|l|}
\hline Relationship & Direct Effect & Indirect Effect & Total Effect & VAF & Type of mediation \\
\hline $\mathrm{RR} \rightarrow \mathrm{IN}$ & 0.255 & & & & \\
\hline $\mathrm{RR} \rightarrow \mathrm{TC} \rightarrow \mathrm{IN}$ & & $0.255^{\star} 0.513=0.131$ & 0.386 & $33.93 \%$ & Partial \\
\hline $\mathrm{PI} \rightarrow \mathrm{IN}$ & 0.356 & & & & \\
\hline $\mathrm{PI} \rightarrow \mathrm{RC} \rightarrow \mathrm{IN}$ & & $0.356^{*} 0.529=0.188$ & 0.544 & $34.56 \%$ & Partial \\
\hline
\end{tabular}

\subsection{Testing of Research Model through fsQCA}

To further validate the hypothesis, the study applies FsQCA by using fsQCA 3.0 software [49] to analyze the relationship between a set of causal variables and the outcome variables. The two main advantages of using FsQCA over traditional techniques are equifinality (i.e., configurations of conditions that can lead to the same outcome) and asymmetry (i.e., the presence and absence of the outcome) [42], which motivates this study to apply FsQCA. Besides, fsQCA leads to a more detailed understanding of the conditions under which the outcome occur than do the regression analyses. Moreover, from a mathematical point of view, fsQCA is equally conclusive to analyses small or large sample sizes, making it a suitable tool for a wide range of research [71].

fsQCA employs a fuzzy dataset to carry out necessary comparisons and gives an alternative quantitative technique for researchers [48]. For analysis, 30 random cases are selected from the dataset. In the fuzzy dataset, the values lie between zero and one, so calibration of data is essential. fsQCA entails the calibration of all conditions and outcomes [48]. Calibration helps to generate a fuzzy-set score that relates to the degree of membership in a set. fsQCA software is utilized to calibrate data into triangular fuzzy set values of 7,5 , and 3 , respectively [49]. To produce these scores, this research identifies the threshold for full membership (fuzzy score $=0.95$ ), full nonmembership (fuzzy score $=0.05$ ), and crossover point (fuzzy score $=0.5$ ) of the conditions. Table 6 shows the cut-off points for each of the conditions and outcomes.

\subsubsection{Necessity Analysis}

Analysis of necessary conditions is the first step in fsQCA. Usually, if the consistency score is higher than the threshold of 0.9 , then the condition or a set of conditions is "necessary" or "almost always necessary" [60]. Table 6 
explains this analysis and elaborates on the presence or absence of outcome variables. In the case of $\mathrm{H} 1$, the presence of RR (fs_RR) turns out to be a necessary condition for the outcome variable TC. Similarly, RTC (fs_RTC) arise to be a necessary condition for $\mathrm{RC}$ in $\mathrm{H} 2$. Other conditions are not necessary for the outcome variables because they are less than the threshold of 0.9 .

Table 6: Necessity condition for $\mathrm{H} 1, \mathrm{H} 2, \mathrm{H} 3$, and $\mathrm{H} 4$

\begin{tabular}{|c|c|c|c|c|c|}
\hline \multirow{2}{*}{$\begin{array}{l}\text { Conditions } \\
\text { Tested }\end{array}$} & \multicolumn{2}{|l|}{ fs_Outcome } & \multirow[t]{2}{*}{ Conditions Tested } & \multicolumn{2}{|l|}{ fs_Outcome } \\
\hline & Consistency & Coverage & & Consistency & Coverage \\
\hline \multicolumn{6}{|c|}{ Analysis of Necessity condition $\mathrm{H} 1$} \\
\hline$f s \_R R \rightarrow f s \_T C$ & 0.963768 & 0.86722 & $\sim f s \_\mathrm{RR} \rightarrow f s \_\mathrm{TC}$ & 0.707114 & 0.71212 \\
\hline \multicolumn{6}{|c|}{ Analysis of Necessity condition H2 } \\
\hline$f s \_\mathrm{CU} \rightarrow f_{s} \mathrm{RC}$ & 0.863315 & 0.900055 & $\sim f s \_\mathrm{CU} \rightarrow f s_{-} \mathrm{RC}$ & 0.667536 & 0.78871 \\
\hline$f s \_\mathrm{EN} \rightarrow f s \_\mathrm{RC}$ & 0.893305 & 0.886078 & $\sim f s \_\mathrm{EN} \rightarrow f s \_\mathrm{RC}$ & 0.727797 & 0.82134 \\
\hline$f s \_H H \rightarrow f s \_R C$ & 0.882735 & 0.884562 & $\sim f_{s} \_\mathrm{HH} \rightarrow f_{S} \_\mathrm{RC}$ & 0.606291 & 0.77123 \\
\hline$f s \_R T C \rightarrow \overline{f s \_R C}$ & 0.915549 & 0.874045 & $\sim f s \_\mathrm{RTC} \rightarrow f s \_\mathrm{RC}$ & 0.655841 & 0.70675 \\
\hline \multicolumn{6}{|c|}{ Analysis of Necessity condition H3 } \\
\hline$f s \_\mathrm{TC} \rightarrow f s_{-} \mathrm{IN}$ & 0.880968 & 0.887352 & $\sim f s \_\mathrm{TC} \rightarrow f s \_\mathrm{IN}$ & 0.690059 & 0.81674 \\
\hline \multicolumn{6}{|c|}{ Analysis of Necessity condition $\mathrm{H} 4$} \\
\hline$f s \_R C \rightarrow f s \_I N$ & 0.86985 & 0.837005 & $\sim f s \_R C \rightarrow f s \_$IN & 0.736494 & 0.79983 \\
\hline
\end{tabular}

\subsubsection{Sufficiency Analysis}

Following Ragin [48], a truth table analysis is also conducted for sufficiency test to attain the possible configuration to achieve the outcome. In this study, a consistency value of 0.80 is set as the threshold level following the study of Navarro [42]. The results of sufficiency analysis given in Table 7 demonstrates the possible causal configuration leading to the outcome variables. From Table 7, we observe that all the constructs have sufficient consistency score, implying that the transactional and relational contracts are sufficient to influence the purchase intention in about $74 \%$ and $61 \%$ cases, respectively. The same is found in the case of RR and the platform interactivity to generate a transactional and relational contract, respectively. Specifically, the truth table analysis indicates that the platform's transactional obligations response to RR in about $77 \%$ of cases, while a high level of platform interactivity develops a relational contract in about $70 \%$ cases. These findings provide further evidence in favor of Hypothesis 1 and Hypothesis 2.

The results showed that fs_IN response to all the constructs included in the empirical model. Specifically, rating and reviews, platform interactivity, transactional contract, and relational contract appeared to be the best possible configuration influencing purchase intention. The results indicate that the model is informative, as all the causal conditions are necessary to explain the outcome. Moreover, these results are very much in line with those obtained from SEM estimations, providing further evidence to believe the idea that psychological contract is essential to determine the purchase intention.

Table 7: Truth table, analysis for the complex situation $(\mathrm{H} 1, \mathrm{H} 2, \mathrm{H} 3$, and $\mathrm{H} 4)$

\begin{tabular}{|c|c|c|c|c|c|}
\hline Casual Configuration & $\begin{array}{l}\text { Raw } \\
\text { Coverage }\end{array}$ & $\begin{array}{l}\text { Unique } \\
\text { Coverage }\end{array}$ & Consistency & $\begin{array}{l}\text { Sol } \\
\text { coverage }\end{array}$ & $\begin{array}{l}\text { Sol } \\
\text { consistency }\end{array}$ \\
\hline \multicolumn{6}{|l|}{ H1: fs_TC = f (fs_RR) } \\
\hline fs_RR & 0.768 & 0.061 & 0.885 & 0.861 & 0.8147 \\
\hline \multicolumn{6}{|c|}{ H2: fs_RC = f (fs_CU, fs_EN, fs_HH, fs_RTC) } \\
\hline$f s \_C U^{*} f s \_E N^{*} f s \_H H^{*} f s \_R T C$ & 0.699 & 0.052 & 0.913 & 0.873 & 0.8301 \\
\hline \multicolumn{6}{|l|}{ H3: fs_IN = f (fs_TC) } \\
\hline fs_TC & 0.7379 & 0.049 & 0.9834 & 0.8336 & 0.8612 \\
\hline \multicolumn{6}{|l|}{ H4: fs_IN = f (fs_RC) } \\
\hline fs_RC & 0.6112 & 0.063 & 0.9513 & 0.8469 & 0.8672 \\
\hline
\end{tabular}

\section{Discussion}

Discussion including main findings, theoretical and managerial implications, limitation, and future research as presented as follow.

\subsection{Main Findings}

The main purpose of this study was to construct and validate this proposed model of psychological contract from the consumers' viewpoint and incorporating Rousseau's psychological contract [9] as a mediator in the study. First, the study validates that social commerce platform interactivity is composed of four multidimensional constructs: content 
usefulness, engaging, human-human, and real-time communication. Though the previous research in the context of e-commerce has addressed platform interactivity, it remained limited only to one or two dimensions rather than considering all of them at the same time [12], [27]. Barreda et al. argued that a unidimensional approach to study the platform interactivity might not be adequate to grasp its intricacy and dimensions [4]. This study provides further evidence that platform interactivity should be used as a multidimensional construct to fully understand its nuances, making it a powerful construct for practitioners.

Second, the results showed a significant impact of platform interactivity on relational contracts. This result is consistent with existing literature that platform interaction significantly impacts the online relations [70] and relational contract in this study. Furthermore, platform interactivity was viewed as an essential construct to establish long-term relationships with its consumers [42]. Thus, an online platform with good interactivity can establish a favorable relational contract with consumers, thereby acquiring the ultimate goal of purchase intention.

Third, the model showed that rating and reviews exhibited a positive effect on TCs. Rating and reviews are the main sources of getting information from actual consumers and also serve as a guideline about the fulfillment of the contractual obligations of the platform for potential consumers. Social contacts and relationships of individuals in an online platform are mostly based on common interests [1] and, therefore, produce affluent information regarding the transaction environment [73], which ultimately leads to a better consumer's decision making.

Fourth, the model and results showed partial mediating effects of relational contracts that impact the relationship between platform interactivity and purchase intention. TCs had also shown partial mediation in rating and reviews and purchase intention. Fifth, we found that TCs had a significant positive effect on purchase intention in the social commerce context. The same was the case with the relational contract. The relational contract had a positive effect on consumers' purchase intention. Higher the perceptions of relational obligations fulfillment higher will be the purchase intentions.

Finally, this study also validated the robustness of the results through different alternative techniques like PLS-SEM and fsQCA. Fuzzy set qualitative comparative analysis (fsQCA) and Regression analysis are developed on two distinctive logics. fsQCA is used to assess sufficient or necessary configurations of conditions that pave a way to the dependent variable whereas; regression analysis calculates the impact of an independent variable on a dependent variable statistically [65]. Moreover, fsQCA may deal with greater leverage than regression techniques in identifying the various factors regarding configurations of conditions and their connections with purchase intentions. Furthermore, fSQCA assists in categorizing parsimonious combination of factors that explains high purchase intentions in this study. So, fSQCA elaborates different conditions or a set of conditions that are necessary.org. or almost always necessary for the outcome variable [60] to answer the research questions raised in this model.

\subsection{Theoretical Implications}

This study contributes to the literature in the following ways. First, the psychological contract incorporates the conviction that the platform is focused on producing certain benefits [41] to shoppers. These specific advantages assist the platform with increased consumer purchase intentions, which are inconceivable without psychological contracts. It also expands the psychological contracts as a crucial extra variable of customer platform relationships in social commerce sites, whereas psychological contracts have already been applied in e-commerce sites [13]. Second, this investigation has improved the comprehension of the psychological contract in social commerce by incorporating platform interactivity and rating and reviews. By fusing platform interactivity in a consumer-platform relationship, this study helps better to comprehend consumers' and platforms' mutual expectations from each other that help enhances online purchase intention. Third, it delivers empirical support for the proposed model of psychological contracts and platform interactivity with its multidimensional constructs in the social commerce context. Fourth, the psychological contract is reached out as an intervening variable in this examination. It tends to be viewed as the connecting instrument between platform interactivity features and consumers' behavioral outcomes. It clarifies consumers' exchange conduct in social commerce sites in a more exact manner.

\subsection{Managerial Implications}

Understanding potential consumers' views about the consumer-platform relationship are vital from a managerial perspective. It will permit customer service representatives liable for inquiries, replies, and to keenly cope with the elements affecting consumers' perceptions about the psychological contract. Concerning social exchange theory [6], reciprocal obligations are demonstrated as a vital factor for initiating a first psychological contract, which affects the progress of the consumer-platform relationship. Our study suggests social commerce platforms to prioritize the fulfillment of the psychological contracts for its loyal consumers first, who later become the power source of attracting new consumers with their reviews and ratings. New consumers may rely on the ratings and recommendations of old consumers for information before making any purchase decision.

Furthermore, platform interactivity fulfills an influential role in enhancing purchase intentions. Instantaneous communication and human-human interactions are precisely the most relevant indicators for building a robust consumer-platform relationship. As a result, the platform must initially focus on its interactive features to capture 
consumers' attention through its useful content and engaging tactics. In this regard, a platform should provide a transparent and user-friendly interface helping consumers to navigate and interact effectively. These distinct features may ease potential consumers influencing their decision-making process.

\subsection{Limitation and Future Research}

Despite the contributions of this study, some research limitations need acknowledgment. The fact that we only analyzed a single social media platform, the Weitao, is the article's significant limitation, but this must be seen as a first step since this is a preliminary study in a long-term academic debate. In addition, this study employed a convenience sample. We encourage future studies to use the snowball or judgmental sampling of general consumers. Second, while this study examined the mediating effect of psychological contracts, future studies should be extended to examine the moderating effect of psychological contracts that can influence consumers' purchase intention in social commerce. Third, the psychological contract literature identifies some factors which affect employee-employer relationships (e.g., trust and satisfaction). Such research could also identify how each variable, individually and cooperatively, impacts consumer purchase intention. Fourth, culture plays a significant role in defining the psyche of consumers, so it is better to add cultural values to improve these types of researches. Finally, our study only focused on Weitao - the extension of the largest online platform in China Taobao. Another suggestion for future research is to examine the different social commerce sites like Facebook or Twitter, and it will produce some exciting results.

\section{Conclusion}

In sum, this study concludes that social commerce is an emerging wave in online business due to its increasing influence on consumers' buying behavior. It developed and examined a mediation model to capture the mutual influence process of two main platform characteristics, rating and reviews, and the platform interactivity, on consumers' purchase intention based on psychological contract perspective. The robustness of the proposed conceptual model was assessed through quantitative (PLS-SEM) and qualitative (fSQCA) analysis, which is scarce in the prevailing literature. The empirical analysis revealed that the effects of rating and reviews and platform interactivity were contingent on psychological contracts. It also indicated precisely that these independent variables were the most prominent constructs to consider in enhancing online purchase intentions. The evidence from this study also suggested that psychological contracts mediated all the relationships significantly.

Moreover, this study had highlighted the relevance and significance of psychological contracts and recognized it as a novel idea to enhance online purchase intentions in the social commerce platform. These findings also added to the growing body of literature that psychological contracts established reciprocal obligations between consumers and platforms that were helped strengthen the proposed model. Furthermore, this study had devised the methodology and utilized currently developed fSQCA along with partial least squares technique to get the valid results of the proposed model and hypotheses. This research obtained a valuable aid for practitioners and social commerce platforms to address the problem of limited purchase intentions by providing a user-friendly interface and delivering successful psychological contract fulfillment. The current study was limited to Weitao for data collection and unable to analyze some different social commerce sites like Facebook or Twitter that could produce some exciting results. Taken together, the results showed that a psychological contract was one of the essential drivers to transform consumer purchase intentions towards the social commerce platform through platform characteristics.

\section{Acknowledgement}

This study is supported by National Key Research and Development Project of China (2019YFD1101104) and the National Natural Science Foundation of China (71874022 and 71431002).

\section{References}

[1] M. Agrebi and A. L. Boncori, What makes a website relational? The experts' viewpoint, European Management Journal, vol. 35, no. 5, pp. 617-631, 2017.

[2] A. S. Al-adwan and H. Kokash, The driving forces of Facebook social commerce, Journal of Theoretical and Applied Electronic Commerce Research, vol. 14, no. 2, pp. 15-32, 2019.

[3] J. S. Armstrong and T. S. Overton, Estimating nonresponse bias in mail surveys, Journal of Marketing Research, vol. 14, no. 3, pp. 396-402, 1977.

[4] A. A. Barreda, A. Bilgihan, K. Nusair, and F. Okumus, Online branding: Development of hotel branding through interactivity theory, Tourism Management, vol. 57, pp. 180-192, 2016.

[5] R. C. Bird, Employment as a relational contract, Journal of Labor and Employment Law, vol. 8, no. 1, 149-216, 2005.

[6] P. M. Blau, Exchange and Power in Social Life. New York: John Wiley, 1964. 
[7] A. H. Busalim and A. R. C. Hussin, Understanding social commerce: A systematic literature review and directions for further research, International Journal of Information Management, vol. 36, no. 6, pp. 1075-1088, 2016.

[8] A. H. Busalim, A. C. H. Razak and A. L. Noorminshah, Factors influencing customer engagement in social commerce websites: A systematic literature review, Journal of Theoretical and Applied Electronic Commerce Research, vol. 14, no. 2, pp. 1-14, 2019.

[9] T. Chang and W. Hsiao, Factors influencing intentions to use social recommender systems: A social exchange perspective, Cyberpsychology, Behavior, and Social Networking, vol. 16, no. 5, pp. 357-363, 2013.

[10] J. Cohen, Statistical Power Analysis for the Behavioural Sciences. NewJersey: Lawrence Erlbaum Associates Hillsdale, 1988

[11] E. Coyle and J. R. Thorson, The effects of progressive levels of interactivity and vividness in web marketing sites, Journal of Advertising, vol. 30, no. 3, pp. 65-77, 2001.

[12] C. N. Faisal, M. Gonzalez-Rodriguez, D. Fernandez-Lanvin, and J. de Anres-Suarez, Web design attributes in building user trust, satisfaction, and loyalty for a high uncertainty avoidance culture, IEEE Transactions on Human-Machine Systems, vol. 47, no. 6, pp. 847-859, 2017.

[13] J. Fogel, S. Zachariah and J. Fogel, Intentions to use the Yelp review website and purchase behavior after reading reviews, Journal of Theoretical and Applied Electronic Commerce Research, vol. 12, no. 1, pp.53-67, 2017.

[14] B. J. Fogg, Prominence-interpretation theory: Explaining how people assess credibility online, in Proceedings of $\mathrm{CHI} 03$ Extended Abstracts on Human Factors in Computing Systems, Ft. Lauderdale, Florida, 2003, pp. 722723.

[15] A. J. Gaskin, S. Godfrey and A. Vance, Successful system-use: It' s not just who you are, but what you do, AIS Transactions on Human-Computer Interaction, vol. 10, no. 2, pp. 57-81, 2018.

[16] M. Grimmer and M. Oddy, Violation of the psychological contract: The mediating effect of relational versus transactional beliefs, Australian Journal of Management, vol. 32, no. 1, pp. 153-174, 2007

[17] R. Hair, J. Black, W. Babin, and B. Anderson, Multivariate Data Analysis (7th Ed.). Upper Saddle River, NJ, USA: Prentice-Hall Inc., 2010.

[18] M. Hajli, A research framework for social commerce adoption, Information Management \& Computer Security, Vol. 21, no. 3, pp. 144-154, 2013.

[19] N. Hajli, Social commerce constructs and consumer's intention to buy, International Journal of Information Management, vol. 35, no. 2, pp. 183-191, 2015

[20] C. Hatch. (2018) Be in the know: 2018 ecommerce statistics you should know. Disruptive Advertising. [Online]. Available: https://www.disruptiveadvertising.com/ppc/ecommerce/2018-ecommerce-statistics/

[21] A. F. Hayes, Introduction to Mediation, Moderation, and Conditional Process Analysis: A Regression-Based Approach. New York: Guilford Publications, 2017.

[22] J. J. Hew, G. W. H. Tan, B. Lin, and K.B. Ooi, Generating travel-related contents through mobile social tourism: does privacy paradox persist?, Telematics Information, vol. 43, no. 7, pp. 914-35, 2017.

[23] J. A. Hill, S. Eckerd, D. Wilson, and D. Greer, The effect of unethical behavior on trust in a buyer-supplier relationship: The mediating role of psychological contract violation, Journal of Operations Management, vol. 27, no. 4, pp. 281-293, 2009

[24] Z. Huang and M. Benyoucef, From e-commerce to social commerce: A close look at design features, Electronic Commerce Research and Applications, vol. 12, no. 4, pp. 246-259, 2013.

[25] I. J. Hwang, B. G. Lee and K. Y. Kim, Information asymmetry, social networking site word of mouth, and mobility effects on social commerce in Korea, Cyberpsychology, Behavior, and Social Networking, vol. 17, no. 2 , pp. 117-124, 2014.

[26] M. Janssens, L. Sels and I. Van den Brande, Multiple types of psychological contracts: A six-cluster solution, Human Relations, vol. 56, no. 11, pp. 1349-1378, 2003.

[27] M. L. Jensen, N. E. Dunbar, M. S. Connelly, W. D. Taylor, M. Hughes, B. Adame, and B. Rozzell, Organizational balancing of website interactivity and control: An examination of ideological groups and the duality of goals, Computers in Human Behavior, vol. 38, pp. 43-54, 2014.

[28] R. P. J. Kingshott, The impact of psychological contracts upon trust and commitment within supplier-buyer relationships: A social exchange view, Industrial Marketing Management, vol. 35, no. 6, pp. 724-739, 2006.

[29] H. Ko, C. H. Cho and M. S. Roberts, Internet uses and gratifications: A structural equation model of interactive advertising, Journal of Advertising, vol. 34, no. 2, pp. 57-70, 2005.

[30] J. M. Kraak, R. Lunardo, O. Herrbach, and F. Durrieu, Promises to employees matter, self-identity too: Effects of psychological contract breach and older worker identity on violation and turnover intentions, Journal of Business Research, vol. 70, pp. 108-117, 2017.

[31] D. C. Li, Online social network acceptance: A social perspective, Internet Research, vol. 21, no. 5, pp. 562-580, 2011.

[32] H. Liang, N. Saraf, Q. Hu, and Y. Xue, Assimilation of enterprise systems: The effect of institutional pressures and the mediating role of top management, MIS Quaterly, vol. 31, no. 1, pp. 59-87, 2007.

[33] K. Lin, and H. Lu, Intention to Continue Using Facebook fan pages from the perspective of social capital theory, Cyberpsychology, Behavior, and Social Networking, vol. 14, no. 10, pp. 565-570, 2011.

[34] D. P. MacKinnon, C. M. Lockwood, J. M. Hoffman, S. G. West, and V. Sheets, A comparison of methods to test mediation and other intervening variable effects, Psychological Methods, vol. 7, no. 1, pp. 83, 2002.

[35] I. R. Macneil, Relational Contract Theory: Unanswered Questions: A Symposium in Honor of Ian R. MacNeil. Chicago, Illinois, 2000. 
[36] G. Marakas, R. Johnson and P. F. Clay, The evolving nature of the computer self-efficacy construct: An empirical investigation of measurement construction, validity, reliability, and stability over time, Journal of the Association for Information Systems, vol. 8, no. 1, pp. 16-46, 2007.

[37] F. J. Mata and A. Quesada, Web 2.0, social networks and e-commerce as marketing tools, Journal of Theoretical and Applied Electronic Commerce Research, vol. 9, no. 1, pp. 56-69, 2014.

[38] S. J. McMillan and J. S. Hwang, Measures of perceived interactivity: An explosion of the role of direction of communication, user control, and time in shaping perceptions of interactivity, Journal of Advertising, vol. 31, no. 3, pp. 29-42, 2002.

[39] R. Miles and C. Snow, Organizational Strategy, Structure and Process. New York: McGrath-Hill Book Company, 1978.

[40] S. Molinillo, F. Liébana-cabanillas and R. Anaya-Sánchez, A social commerce intention model for traditional ecommerce sites, Journal of Theoretical and Applied Electronic Commerce Research, vol. 13, no. 2, pp. 80-93, 2018.

[41] E. W. Morrison and S. L. Robinson, When employees feel betrayed: A model of how psychological contract violation develops, Academy of Management Review, vol. 22, no. 1, pp. 226-256, 1997.

[42] S. Navarro, C. Llinares and D. Garzon, Exploring the relationship between co-creation and satisfaction using QCA, Journal of Business Research, vol. 69, no. 4, pp. 1336-1339, 2016.

[43] B. Neelotpaul, A study on interactivity and online branding, Advances in Management, vol. 3, no. 3, pp. 13-17, 2010.

[44] P. Palla, R. H. Tsiotsou and Y. T. Zotos, Is website interactivity always beneficial? An elaboration likelihood model approach, in Proceedings of Advances in Advertising Research, vol. IV, Springer Gabler, Wiesbaden, 2013, pp. 131-145.

[45] A. Parasuraman, V. A. Zeithaml and L. L. Berry, A conceptual model of service quality and its implications for future research, Journal of Marketing, vol. 49, no. 4, pp. 41-50, 1985.

[46] P. A. Pavlou and D. Gefen, Psychological contract violation in online marketplaces: Antecedents, consequences, and moderating role, Information Systems Research, vol. 16, no. 4, pp. 372-399, 2005.

[47] P. M. Podsakoff, S. B. MacKenzie, J. Y. Lee, and N. P. Podsakoff, Common method biases in behavioral research: a critical review of the literature and recommended remedies, Journal of Applied Psychology, vol. 88, no. 5 , p. 879, 2003

[48] C. C. Ragin, Redesigning Social Inquiry: Fuzzy Sets and Beyond. Chicago, IL: Chicago University Press, 2008.

[49] C. C. Ragin and S. Davey, Fuzzy-Set/Qualitative Comparative Analysis. Irvine, California, University of California, 2014.

[50] O. C. Richard, A. McMillan-Capehart, S. N. Bhuian, and E. C. Taylor, Antecedents and consequences of psychological contracts: Does organizational culture really matter?, Journal of Business Research, vol. 62, no. 8, pp. 818-825, 2009.

[51] C. M. Ridings and D. Gefen, Virtual community attraction: Why people hang out online, Journal of ComputerMediated Communication, vol. 10, no. 1, 2004

[52] S. L. Robinson and E. W. Morrison, Psychological contracts and organisational citizenship behaviour: The effects of unfulfilled obligations, Journal of Organizational Behavior, vol. 15, pp. 289-298, 1995.

[53] S. L. Robinson and D. M. Rousseau, Violating the psychological contract: Not the exception but the norm, Journal of Organizational Behavior, vol. 15, no. 3, pp. 245-259, 1994.

[54] D. M. Rousseau, Psychological and implied contracts in organizations, Employee Responsibilities and Rights Journal, vol. 2, no. 2, pp. 121-139, 1989.

[55] D. M. Rousseau, New hire perceptions of their own and their employer's obligations: A study of psychological contracts, Journal of Organizational Behavior, vol. 11, no. 5, pp. 389-400, 1990.

[56] D. M. Rousseau and S. A. Tijoriwala, Assessing psychological contracts: Issues, alternatives and measures, Journal of Organizational Behavior: The International Journal of Industrial, Occupational and Organizational Psychology and Behavior, vol. 19, no. S1, pp. 679-695, 1998

[57] F. Ryan, Round Hall nutshells Contract Law. Thomson Round Hall, 2006.

[58] L. Salvatori and F. Marcantoni, Social commerce: A literature review, in Proceedings of Science and Information Conference (SAI), London, 2015, pp. 257-262.

[59] A. Schlosser, Harnessing the power of interactivity: Implications for consumer behavior in online environments, in Advances in Consumer Research (S. J. Hoch and R. J. Meyer, Eds.). Valdosta, GA: Association for Consumer Research, 2000, pp. 79-87.

[60] M. R. Schneider, C. Schulze-Bentrop and M. Paunescu, Mapping the institutional capital of high-tech firms: A fuzzy-set analysis of capitalist variety and export performance, Journal of International Business Studies, vol. 41, no. 2, pp. 246-266, 2010.

[61] G. Sharma and W. Lijuan, The effects of online service quality of e-commerce websites on user satisfaction, Electronic Library, vol. 33, no. 3, 2015.

[62] A. Sperber, R. Devellis and B. Boehlecke, Cross-cultural translation: Methodology and validation, Journal of Cross Culture Psychology, vol. 25, pp. 501-524, 1994.

[63] Statista. (2018) Average value of global online shopping orders as of 1st quarter 2018. Statista. [Online]. Available: https://www.statista.com/statistics/325384/online-shopping-order-values-traffic-source/

[64] S. Stackd. (2016) Why is interactivity an important element in website design?. Stackd Design. [Online]. Available: https://www.stackddesign.com/blog/2016/07/25/interactivity-important-element-website-design/ 
[65] D. Stockemer, Fuzzy set or fuzzy logic? Comparing the value of qualitative comparative analysis (fsQCA) versus regression analysis for the study of women's legislative representation, European Political Science, vol. 12, no. 1, pp. 86-101, 2013.

[66] N. Urbach and F. Ahlemann, Structural equation modeling in information systems research using partial least squares, Journal of Information Technology Theory and Application, vol. 11, no. 2, pp. 5-40, 2010.

[67] J. Wade. (2017) Why social commerce will take off in 2018. Smart Insights. [Online]. Available: https://www.smartinsights.com/digital-marketing-strategy/social-commerce-will-take-off-2018/

[68] H. Wijnholds and M. W. Little, Regulatory issues for global E-tailers: Marketing implications, Academy of Marketing Science Review, pp. 1-15, 2001.

[69] J. Weisberg, D. Te'eni and L. Arman, Past purchase and intention to purchase in e-commerce: the mediation of social presence and trust, Internet Research, vol. 21, no. 1, pp. 82-96, 2011.

[70] B. Wellman, J. Salaff, D. Dimitrova, L. Garton, M. Gulia, and V. Haythornthwaite, Computer networks as social networks: Collaborative work, telework, and virtual community, Annual Review of Sociology, vol. 22, no. 1, pp. 213-238, 1996.

[71] A. G. Woodside, Proposing a new logic for data analysis in marketing and consumer behavior: Case study research of large- $N$ survey data for estimating algorithms that accurately profile $X$ (extremely high-use) consumers, Journalof Global Scholars of Marketing Science, vol. 22, no. 4, pp. 277-289, 2012.

[72] B. Xiao, M. Huang and A. J. Barnes, Electronic commerce research and applications network closure among sellers and buyers in social commerce community, Electronic Commerce Research and Applications, vol. 14, no. 6 , pp. 641-653, 2015

[73] M. S. Yadav and R. Varadarajan, Interactivity in the electronic marketplace: An exposition of the concept and implications for research, Journal of the Academy of Marketing Science, vol. 33, no. 4, pp. 585-603, 2005.

[74] L. Zhao and Y. Lu, Enhancing perceived interactivity through network externalities: An empirical study on microblogging service satisfaction and continuance intention, Decision Support Systems, vol. 53, no. 4, pp. 825-834, 2012.

[75] X. Zhao, J. G. Lynch Jr, and Q. Chen, Reconsidering Baron and Kenny: myths and truths about mediation analysis, Journal of Consumer Research, vol. 37, no. 2, pp. 197-206, 2010. 


\section{Appendix A: Measurement Items}

\begin{tabular}{|c|c|c|}
\hline Items & Description & Factor loading \\
\hline \multicolumn{3}{|c|}{ Rating and reviews [19] } \\
\hline RR1 & The credit rating on the platform is high. & 0.822 \\
\hline RR2 & The platform has a large number of fans. & 0.891 \\
\hline RR3 & There are a lot of reviews on the platform. & 0.868 \\
\hline \multicolumn{3}{|c|}{ Relational contract [39][41] } \\
\hline RC1 & The platform sincerely provides me with reliable, relieved, and high-quality service. & 0.873 \\
\hline $\mathrm{RC2}$ & The platform really respects me, never perfunctory. & 0.871 \\
\hline RC3 & $\begin{array}{l}\text { The platform attaches great importance to establish a long-term relationship with } \\
\text { me. }\end{array}$ & 0.844 \\
\hline RC4 & The platform is really concerned about my shopping experience. & 0.895 \\
\hline RC5 & The platform attaches importance to establishing a personal friendship with me. & 0.791 \\
\hline RC6 & I can feel the platform's sincerity. & 0.801 \\
\hline \multicolumn{3}{|c|}{ Transactional contract [46] } \\
\hline TC1 & $\begin{array}{l}\text { The platform does not seem likely to have a fraudulent attempt (e.g., collecting } \\
\text { money and not delivering the product, product quality deception, selling counterfeit } \\
\text { products). }\end{array}$ & 0.773 \\
\hline TC2 & $\begin{array}{l}\text { I believe the product will be the same in quality and design as described by the } \\
\text { platform. }\end{array}$ & 0.815 \\
\hline TC3 & $\begin{array}{l}\text { The platform is not likely to break the contract (e.g., refuse to deliver and return the } \\
\text { product). }\end{array}$ & 0.834 \\
\hline TC4 & The product will reach on time without delay. & 0.811 \\
\hline TC5 & The platform can offer product guarantees (e.g., product refund, return, warranties). & 0.831 \\
\hline \multicolumn{3}{|c|}{ Content usefulness [29] } \\
\hline CU1 & I would click into deeper links. & 0.811 \\
\hline CU2 & I would stay longer for details. & 0.815 \\
\hline CU3 & $\begin{array}{l}\text { The platform also provides different multimedia functions such as pictures and } \\
\text { videos for product presentation. }\end{array}$ & 0.878 \\
\hline CU4 & $\begin{array}{l}\text { The platform provides a search function to find out exact products according to my } \\
\text { needs. }\end{array}$ & 0.864 \\
\hline \multicolumn{3}{|c|}{ Engaging [38] } \\
\hline EN1 & The platform has a variety of content. & 0.877 \\
\hline EN2 & The platform keeps my attention. & 0.847 \\
\hline EN3 & It's easy to find my way through the platform. & 0.831 \\
\hline EN4 & The platform provides immediate answers to my questions. & 0.856 \\
\hline \multicolumn{3}{|c|}{ Human-human [29] } \\
\hline $\mathrm{HH} 1$ & I would participate in customer discussions. & 0.866 \\
\hline $\mathrm{HH} 2$ & I would provide my feedback to the platform. & 0.805 \\
\hline $\mathrm{HH} 3$ & I would like to contact the seller. & 0.867 \\
\hline $\mathrm{HH} 4$ & $\begin{array}{l}\text { I would sign in at the platform for information purposes. (Sometimes people sign in } \\
\text { some websites only for getting information and websites send those blogs, articles, } \\
\text { new launches, and new offers, etc.) }\end{array}$ & 0.865 \\
\hline \multicolumn{3}{|c|}{ Real-time communication [38] } \\
\hline RTC1 & The platform enables two-way communication. & 0.836 \\
\hline RTC2 & The platform enables concurrent communication. & 0.839 \\
\hline RTC3 & The platform is interactive. & 0.874 \\
\hline RTC4 & The platform is interpersonal. & 0.784 \\
\hline RTC5 & The platform enables conversation. & 0.860 \\
\hline \multicolumn{3}{|c|}{ Purchase intention [19] } \\
\hline IN1 & It is very likely that I will purchase from this platform. & 0.886 \\
\hline IN2 & There is a high probability that I would purchase from this platform. & 0.864 \\
\hline IN3 & I will consider buying products from this platform. & 0.821 \\
\hline IN4 & My willingness to purchase from this platform will be high. & 0.838 \\
\hline
\end{tabular}

